\title{
Effects of salmon lice Lepeophtheirus salmonis on sea trout Salmo trutta at different times after seawater transfer
}

\author{
Leigh H. J. Dawson ${ }^{1, *}$, Alan W. Pike ${ }^{2}$, Dominic F. Houlihan ${ }^{2}$, Alasdair H. McVicar ${ }^{3}$ \\ ${ }^{1}$ Station Méditerranéenne de l'Environnement Littoral, 1 Quai de la Daurade, F-34000 Sète, France \\ ${ }^{2}$ Department of Zoology, University of Aberdeen, Tillydrone Avenue, Aberdeen AB24 2TZ, Scotland, UK \\ ${ }^{3}$ SOAEFD Marine Laboratory, PO Box 101, Victoria Road, Torry, Aberdeen AB11 9DB, Scotland, UK
}

\begin{abstract}
The physiological and behavioural effects and skin damage caused by salmon lice Lepeophtheirus salmonis (Kroyer) infections on sea trout Salmo trutta L. smolts were greater in fish infected with lice 2 wk after seawater transfer than in fish infected $6 \mathrm{wk}$ after seawater transfer. The initial prevalence of infection was $100 \%$ for both groups and the intensity of infection decreased significantly with time over $5 \mathrm{wk}$. Significantly fewer of the fish infected $2 \mathrm{wk}$ after seawater transfer had resumed feeding by the end of the experiment, leading to a loss of body condition. Furthermore, these fish suffered more severe damage to the skin and detrimental changes in physiological integrity than fish infected $6 \mathrm{wk}$ after seawater transfer as a direct consequence of feeding preadult lice, leading to osmoregulatory failure and death. Although this study was carried out in laboratory conditions, results indicate that lice infections may potentially have a detrimental impact on the survival of wild smolts after seawater transfer
\end{abstract}

KEY WORDS: Salmon lice - Sea trout - Seawater transfer - Osmoreulatory failure $\cdot$ Skin damage

\section{INTRODUCTION}

In the last decade, there has been a decline in sea trout Salmo trutta L. populations in the northern Atlantic, characterised by the early return of emaciated sea trout smolts to freshwater infected with juvenile salmon lice Lepeophtheirus salmonis (Krøyer) (Anonymous 1991), henceforth called lice. The latter stages of this decline coincided with the rise in the aquaculture industry in western Ireland and northwestern Scotland (Anonymous 1991) and lead to the hypothesis that lice emanating from salmon farms may be a source of infection for wild salmonid populations migrating to the sea (Tully 1992).

During the decline of sea trout in western Ireland, smolts appeared in the estuaries of rivers for a 3 to $5 \mathrm{wk}$ period after entering seawater, indicating that lice infections occurred within 2 or $3 \mathrm{wk}$ of migration to the sea (Tully \& Whelan 1993). One of the features of seawater

•E-mail: ldawson@crit.univ-montp2.fr transfer is suppression of appetite, leading to a decrease in growth performance which may last for up to $30 \mathrm{~d}$ (Usher et al. 1991, Jørgensten \& Jobling 1994, Stead et al. 1996). Preadult lice also induce appetite suppression, coupled with physiological changes and mechanical damage to the head and operculum of artificially infected post-smolt Atlantic salmon (Anonymous 1997) Therefore, fish infected after seawater transfer may not have the ability to recover from the effects of preadult lice, resulting in morbidity or mortality of smolts. This work aimed to determine the physiological and behavioural effects and skin damage caused by lice infections in sea trout infected during and after the critical first $2 \mathrm{wk}$ after seawater transfer, when any disruption may have serious consequences for the survival of the fish.

\section{MATERIALS AND METHODS}

Maintenance of fish and artificial infection. Hatchery-reared sea trout $(n=360$, range 57.6 to $100.7 \mathrm{~g}$ ) 
were held in circular tanks $(1 \mathrm{~m}$ diameter, $400 \mathrm{l}$ continuously aerated fresh water) at the Marine Laboratory experimental unit at Aultbea, Wester Ross. The fish were divided randomly into 12 tanks $(n=30)$ and after an acclimation period of $3 \mathrm{wk}$, fresh water in all tanks was replaced with ambient seawater, supplied at a rate of $101 \mathrm{~min}^{-1}$ until the end of the experiment. All fish were fed a commercial pellet diet (Trouw) at $2 \%$ body weight $\mathrm{d}^{-1}$ in $15 \mathrm{~min}$ on/off pulses during daylight hours and were maintained under natural photoperiod, ambient seawater temperature $\left(10.7\right.$ to $\left.13.9^{\circ} \mathrm{C}\right)$ and ambient salinity (34.2 to $34.4 \%$ ) throughout the experiment.

Fish tanks were divided into 2 groups for infection with lice at 2 or $6 \mathrm{wk}$ after seawater transfer. Two weeks after seawater transfer, 3 tanks of fish were exposed to approximately 750 infective copepodids per tank under conditions of low water levels and high aeration for $3 \mathrm{~h}$. Another 3 tanks were treated in a similar manner to the infected group except that there was no exposure to copepodids. These fish were denoted as Week-2-infected and Week-2-control fish. Six weeks after seawater transfer, 3 of the remaining 6 tanks of fish were infected as before and 3 tanks were maintained as controls. These fish were denoted as Week-6-infected and Week-6-control fish. The experiment was designed to allow an overlap of the last sample day of the Week-2 and the first sample day of the Week-6 control groups.

Data compilation and statistical analyses. At weekly intervals from 1 to 5 wk post-infection, 5 fish from each tank were killed by a lethal dose of anaesthetic (MS222, Sigma), weighed and measured and the condition factor $K\left(\mathrm{~g} \mathrm{~cm}^{-1}\right)$ was determined by the equation (Jørgensen \& Jobling 1994):

$$
K=\frac{W}{L^{b}} \times 100
$$

where $W$ is the final wet weight $(\mathrm{g}), L$ is the fork length $(\mathrm{cm})$ and $b$ is the slope coefficient of the regression of $\log _{10}$ weight on $\log _{10}$ length (Le Cren 1951, Bolger \& Connolly 1989).

The gut was removed and examined for the presence of food and the percentage of feeding fish was collated for each group. Dorsal fin erosion was estimated by eye, and grouped into 4 arbitrary categories: $0=0 \%$ erosion; $1=<33 \%$ erosion; $2=33-66 \%$ erosion; $3=>66 \%$ erosion. The extent of skin damage was estimated for 3 regions of each fish [head region (head and operculum), anal region (behind the anal fin) and dorsal region (dorsal ridge)], and grouped into 5 categories (Table 1).
Blood was collected from the caudal vein, centrifuged at $10000 \times g$ for $15 \mathrm{~min}$ and the serum stored at $-70^{\circ} \mathrm{C}$. The serum was subsequently tested for glucose, chloride, total protein and serum albumen using a random access autoanalyser (RA-XT; Technicon). The number and developmental stages of lice were recorded for all infected fish.

Statistical analyses were carried out using the Minitab statistical package and the data are presented as means and standard errors or as percentages. One-way analysis of variance (ANOVA) and Kruskal-Wallis tests were used to examine significant differences between groups of fish from replicate tanks. Differences between the data collected from the first and last sample days of the Week- 6 and Week- 2 control groups respectively were determined using $t$-tests, Mann-Whitney $U$-tests, chi square and Friedman's tests. One-way ANOVA tests were used to determine significant differences in mean number of lice, and 2-way ANOVA tests were used to examine differences in condition factor within and between the groups of fish and the relationship between and condition factor and time. Tukey tests were used to identify the groups which were significantly different from each other at the $5 \%$ level. Twoway ANOVA and Friedman's test were used to examine significant differences between the physiological parameters measured. Kruskal-Wallis tests were used to determine differences in total fish mortality and total feeding fish between groups. Friedman tests were used to examine differences in weekly lice developmental stages and morphological damage.

\section{RESULTS}

\section{Development and survival of lice}

The prevalence of lice infection was $100 \%$. There were no significant differences in mean lice numbers ( $p>0.05$ ) (Fig. 1), or developmental rate $(p>0.05)$

Table 1. Salmo trutta. Categories of skin damage on sea trout for head (head and operculum), dorsal surface (along dorsal ridge from behind the head to the caudal fin on the dorsal surface) and anal region (behind the anal fin on the ventral surface)

\begin{tabular}{|lll|}
\hline Category & Head and dorsal surface & Anal region \\
\hline 0 & No grazing & No grazing \\
1 & Slight grazing & Slight grazing \\
2 & No obvious lesion but bleeding & No obvious lesion but bleeding \\
when removed from water & when removed from water \\
3 & Open lesion and bleeding & Open lesion and bleeding \\
4 & Muscle/skull exposed & $\begin{array}{c}\text { Lesion bigger than thumbnail } \\
\text { and bleeding }\end{array}$ \\
& & \\
\hline
\end{tabular}




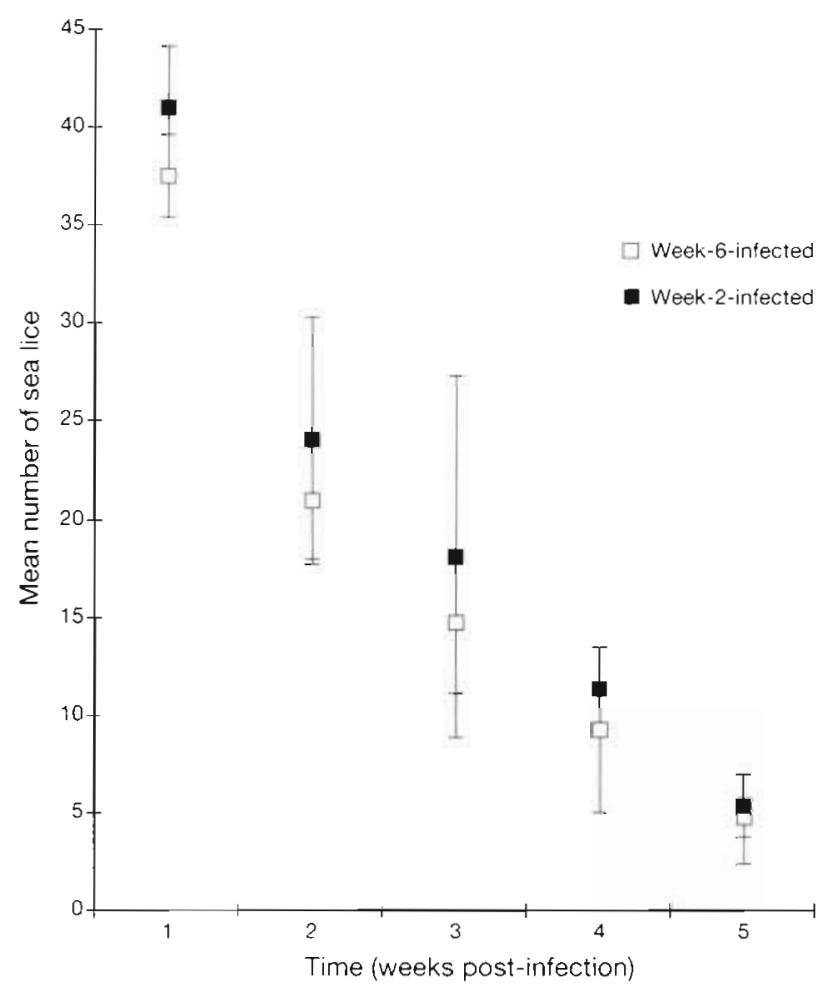

Fig. 1. Lepeophtheirus salmonis infecting Salmo trutta. Mean number of lice $( \pm \mathrm{SE}$ ) on Week-2- and Week-6-infected fish, 1 to $5 \mathrm{wk}$ post-infection. $\mathrm{N}=15$ for all groups except the Week 5 sample of Week-2-infected fish, $N=6 . N=$ total number of fish

(Fig. 2) between the Week-2-infected and Week-6infected fish throughout the experiment.

The percentages of lice surviving from Week 1 to Week 5 were similar for both groups, and there was a significant decrease in the survival of lice between each consecutive sampling week ( $\mathrm{p}=0.02)$ (Table 2 ). Two weeks post-infection, 69.6\% (Week-6-infected fish) and 56.1\% (Week-2-infected fish) of lice survived from the initial infection and more than half in both groups were chalimus, preadult I males and females (Fig. 2). All lice were mobile by $3 \mathrm{wk}$ postinfection and $1 \%$ of the lice on Week- 6 fish were in pre-copulatory pairs ( $p<0.001$ ) (Fig. 2), but there was no significant difference in the mean numbers of lice between Weeks 2 and 3 or between Weeks 3 and 4 ( $p>0.05)$. At $4 \mathrm{wk}$ post-infection, approximately $80 \%$ of all lice were adult stages, but preadult II females and copular pairs of adult males and preadult II females were recorded (Fig, 2). Mating was complete by $5 \mathrm{wk}$ post-infection in both groups of fish and all lice were adult males, females or gravid females (Fig. 2). A significant decrease in lice numbers was recorded in Week-2-infected fish between Weeks 3 and 4 ( $p<0.001)$, but not in the Week-6-infected fish $(p>0.05)$ (Fig. 1).
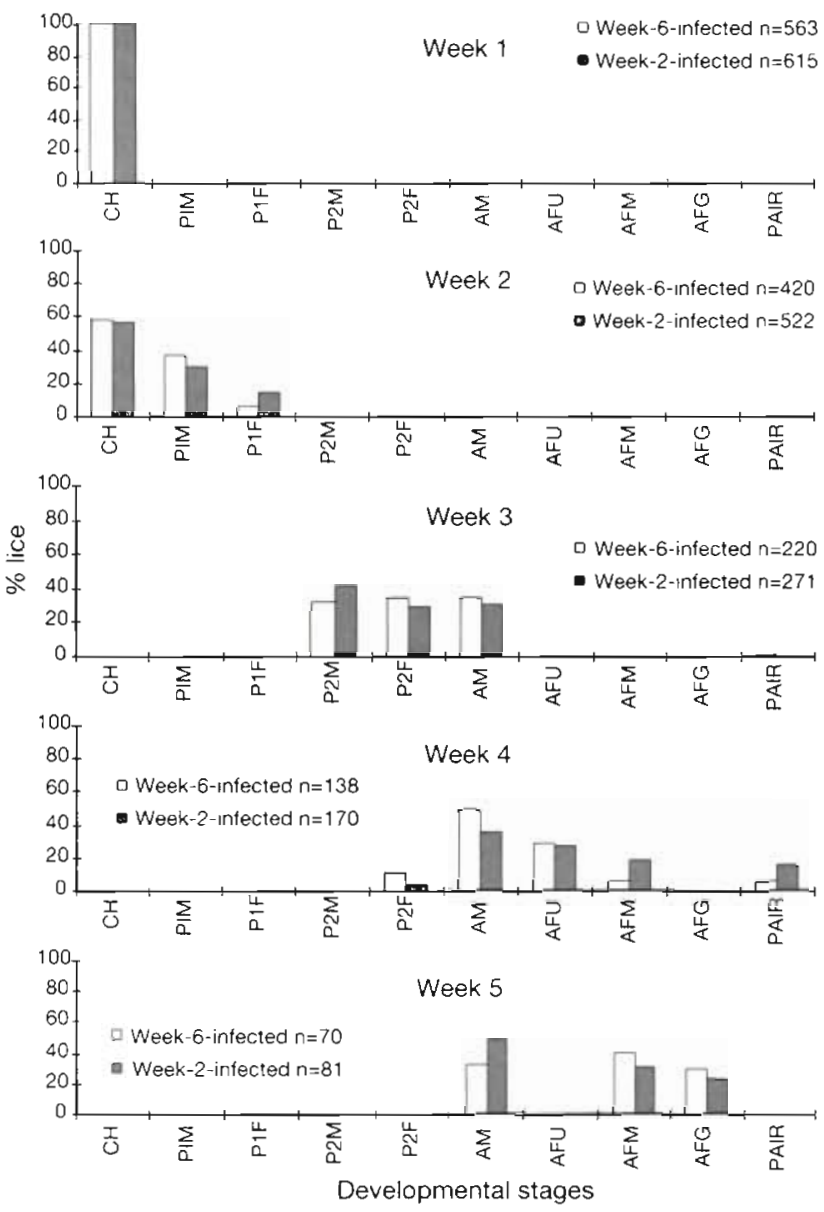

Fig. 2. Lepeophtheirus salmonis infecting Salmo trutta. Frequency distribution $(\%)$ of developmental stages of lice on Week-2- and Week-6-infected fish, 1 to 5 wk post-infection. $\mathrm{CH}$ : all chalimus; P1M: preadult I male; P1F: preadult I female; P2M: preadult Il male; P2F: preadult II female; AM: adult male; AFU: adult female, unmated; AFM: adult female mated; AFG: adult female gravid; PAIR: adult male and pre-adult II female in copula; $\mathrm{n}=$ total number of lice. $\mathrm{N}=15$ for all groups except the Week 5 sample of Week-2infected fish, $N=6 . N=$ total number of fish

\section{Fish mortality}

There were no mortalities recorded at the first sample day of the Week-6 control group or the last sample day of the Week-2 control group (Fig. 3). Significantly fewer mortalities were recorded in the Week-6-control fish at Weeks $1(\mathrm{p}=0.02)$ and $2(\mathrm{p}<0.001)$, but there were no significant differences between any of the groups $3 \mathrm{wk}$ post-infection ( $\mathrm{p}>0.05$ ). At 4 and $5 \mathrm{wk}$ post-infection, Week-6-infected and Week-6-control fish had significantly fewer mortalities than Week-2infected and Week-2-control $(p=0.016)$. The number of mortalities increased significantly each week from 1 to $5 \mathrm{wk}$ post-infection in the Week-6-infected and Week-6-control fish $(p<0.001)$ but increased signifi- 
Table 2. Lepeophtheirus salmonis infecting Salmo trutta. Percentage survival of lice on Week-2-and Week-6-infected fish at 1 to 5 wk post-infection

\begin{tabular}{|lcc|}
\hline \multirow{2}{*}{ Week } & \multicolumn{2}{c|}{ Percentage of lice } \\
& Week-2-infected & Week-6-infected \\
\hline 1 & 82.0 & 75.1 \\
2 & 69.6 & 56.1 \\
3 & 36.2 & 29.3 \\
4 & 22.7 & 18.4 \\
5 & 10.8 & 9.3 \\
\hline
\end{tabular}

cantly only between Weeks 4 and 5 for the Week-2infected fish $(\mathrm{p}<0.001)$, leaving a sample of 6 fish in the Week-2-infected group.

\section{Fish condition and feeding}

No significant differences were found in condition factor between Week 1 of the Week-6-control fish and Week 5 of the Week-2-control fish ( $p>0.05$; $t$-test). The
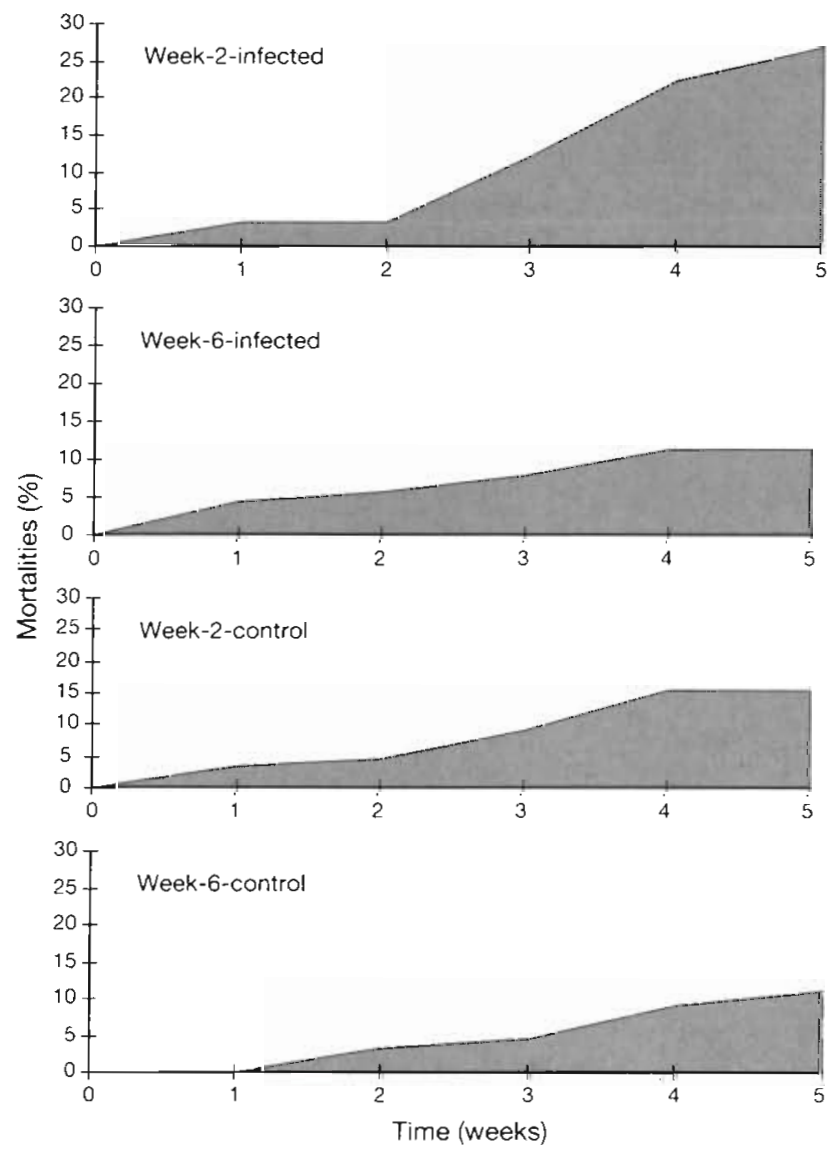

Fig. 3. Salmo trutta. Percentage fish mortality for infected and control fish, 1 to $5 \mathrm{wk}$ post-infection. Week-2-infected, $\mathrm{N}=24$; Week-6-infected, $\mathrm{N}=10$; Week-2-control, $\mathrm{N}=14$; Week-6control, $\mathrm{N}=10 . \mathrm{N}=$ total number of fish condition factor of the Week-6-infected and control groups did not change with time ( $p>0.05)$, but significant differences were found between the first and last 2 sample days in the Week-2-control groups $(\mathrm{p}=0.019)$ (Fig. 4). No significant differences were found in condition factor between any of the groups of fish in the first $2 \mathrm{wk}$ and the 4 th $w \mathrm{k}$ post-infection $(\mathrm{p}>0.05)$. However, at 3 wk post-infection, there was a significant difference in condition factor between the Week-6control fish and the Week-2-infected and control groups ( $p<0.001)$. On the last sample day, the condition factor of the Week-6-control fish was significantly greater than all other groups of fish $(p<0.001)$.

At Week 1 of the Week-6-control fish, only 4 fish had food in the gut compared with 7 of the Week-2-control fish at Week 5 , but this was not statistically significant ( $p>0.05$; chi square) (Fig. 4). None of the fish in the Week-2-infected group had gut contents in any of the sample days and Week-6-infected fish had no gut contents at 3 and 4 wk post-infection, although there were some feeding fish in both the Week- 6 and Week- 2 control groups. The number of feeding fish for the experiment was significantly different between the control groups and the Week-6-infected groups $(p=0.007)$

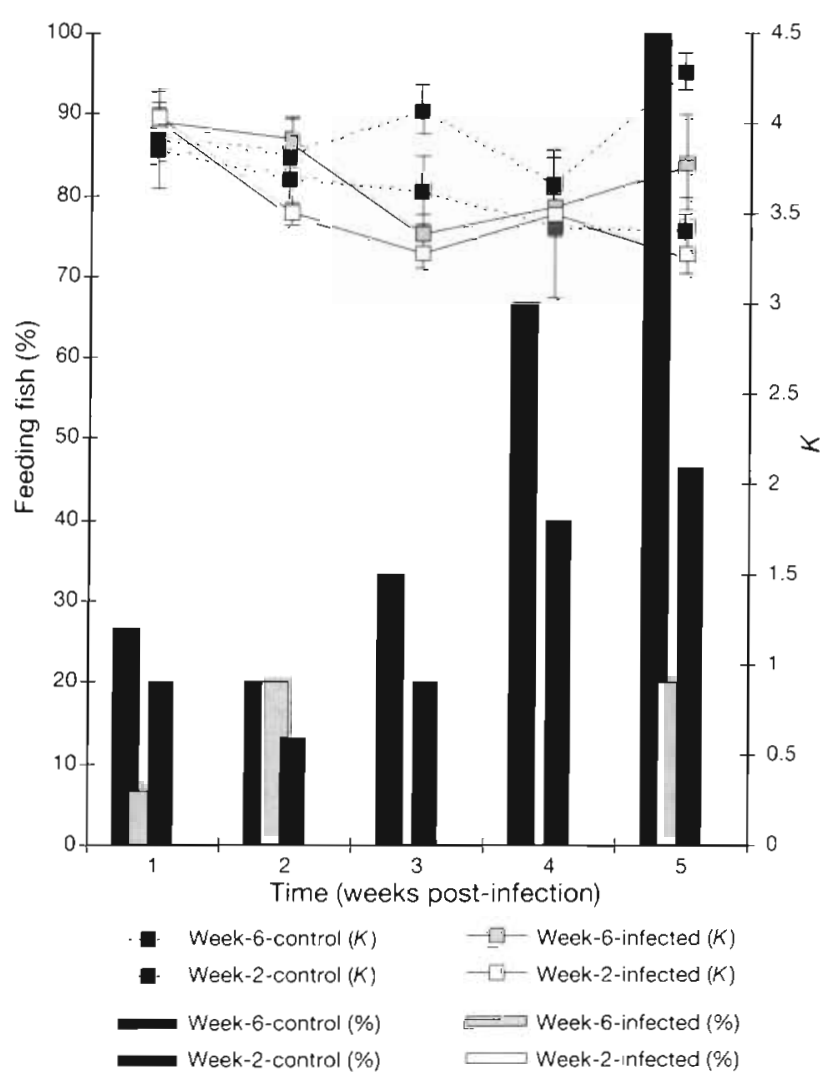

Fig. 4. Salmo trutta. Percentage of feeding fish and condition factor $(K)$ of infected and control fish, 1 to $5 \mathrm{wk}$ post-infection. $\mathrm{N}=15$ for all groups except the Week 5 sample of Week-2infected fish, $N=6 . N=$ total number of fish 
and the control groups and the Week-2-infected groups ( $p<0.001$ ), but no significant differences were found between the contral groups ( $p>0.05)$.

\section{Skin damage}

Control fish had either category 0 or 1 dorsal fin erosion and infected fish had either category 1 or 2 dorsal fin erosion (Table 3 ). Significantly more of the fish in the infected groups had category 2 and 3 dorsal fin erosion compared with the control fish $(p<0.001)$ (Table 3).

Head, dorsal and anal region lesions were not apparent on any of the control fish and therefore all fish in the control groups were denoted as having category 0

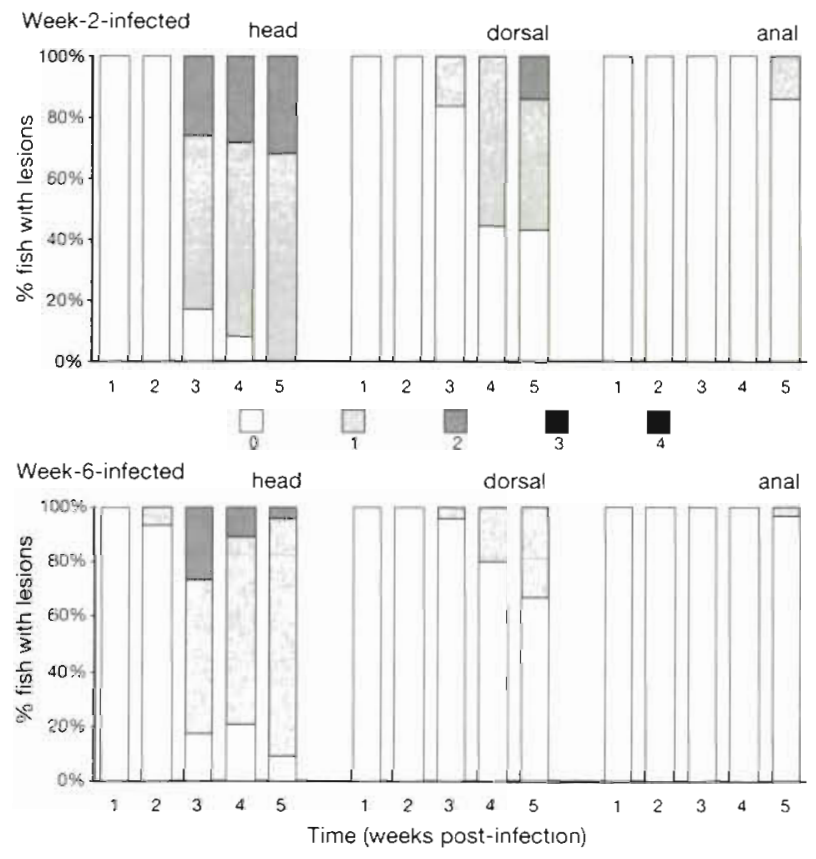

Fig. 5. Salmo trutta. Percentage of fish with head, dorsal and anal lesions (refer to Table 1 for explanation of categories 0 to 4$) 1$ to $5 \mathrm{wk}$ post-infection. $\mathrm{N}=15$ for all groups except the Week 5 sample of Week 2-infected fish, $N=6 . N=$ total number of fish

Table 3. Salmo trutta. Percentage of dorsal fin erosion for Week-2- and Week-6infected and control sea trout (Weeks 1 to 5 ) in categories 0 to 3 where $0=$ $0 \%$ erosion, $1=<33 \%$ erosion, $2=33-66 \%$ erosion and $3=>66 \%$ erosion

\begin{tabular}{|ccccc|}
\hline \multirow{2}{*}{ Category } & \multicolumn{5}{c|}{$\begin{array}{c}\text { Percentage of fish } \\
\end{array}$} & Week-6-control & Week-2-control & Week-6-infected & Week-2-infected \\
\hline 0 & 13.33 & 17.33 & 0 & 0 \\
1 & 80.00 & 81.33 & 10.67 & 4.54 \\
2 & 6.67 & 1.33 & 88.00 & 90.91 \\
3 & 0 & 0 & 1.33 & 4.55 \\
\hline
\end{tabular}

lesions. Head lesions appeared on the Week-6infected fish before the Week-2-infected fish $(p=0.03)$ but a greater number of Week-2-infected fish developed category 2 head lesions ( $p=0.002$ ), category 2 dorsal ridge erosion $(\mathrm{p}=0.01)$ and category 1 anal lesions ( $p=0.009$ ) by the last sampling day (Fig. 5).

\section{Physiological parameters}

Both infected groups had significantly higher chloride levels than the control groups at $3 \mathrm{wk}$ post-infection (Week 2, $p=0.012$; Week-6, $p=0.031$ ) (Fig. 6A). No significant differences were found in glucose levels between any of the groups or any weeks ( $p>0.05)$, although elevated glucose levels were recorded in the Week-2-infected fish at Weeks 3 and 4 (Fig. 6B). Both total protein and serum albumen decreased significantly in the Week-2-infected fish ( $p=0.03)$ and were significantly reduced at Week 3 in the Week-6infected fish ( $p=0.008$ ) (Fig. 6C, D). No significant differences were found between the control groups between sampling weeks, in any of the physiological parameters measured $(p>0.05)$.

\section{DISCUSSION}

No significant differences in lice intensity were found between the fish infected with lice $2 \mathrm{wk}$ after seawater transfer and fish infected 6 wk after seawater transfer, but a lower percentage of lice was recorded on those fish infected after $6 \mathrm{wk}$ in seawater. Smoltification is a period of immunosuppression and leucopenia, associated with elevated cortisol levels (Ellis 1981, Maule et al. 1993), and therefore the trend of lower lice numbers on the fish infected 6 wk after seawater transfer may be a consequence of stronger or faster immune response to lice. Host tissue responses of coho Oncorhynchus kisutch (Walbaum) and chinook Oncorhynchus tshawytscha (Walbaum) salmon to developing chalimus larvae have been shown to impair development and reduce lice infections with time (Johnson \& Albright 1992a, b) and active host rejection of Lernaea cyprinacea by cellular responses has been demonstrated (Woo \& Shariff 1990). However, immunological changes associated with smoltification are complex and merit further study.

The time of seawater transfer had no effect on the developmental rate of Lepeophtheirus salmonis. Some lice had formed pre-copulatory pairs on the groups of fish infected $6 \mathrm{wk}$ after 

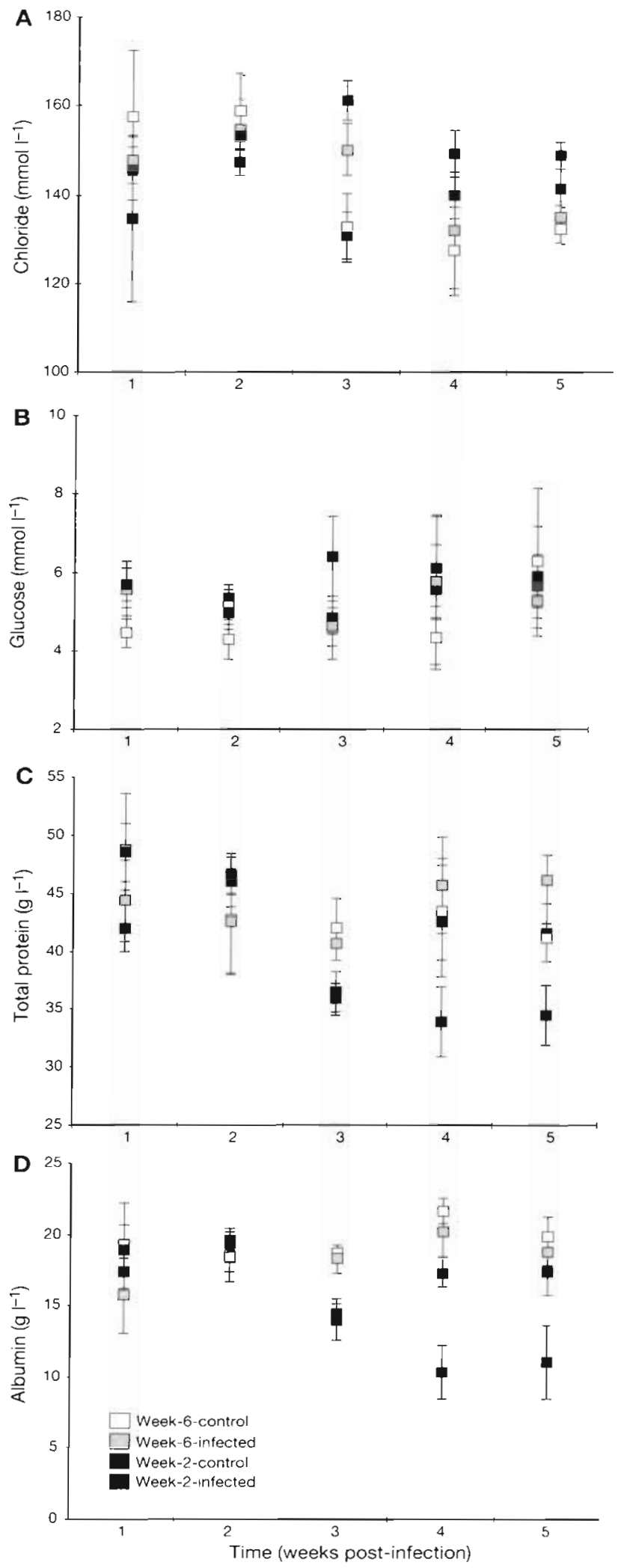

Fig. 6. Salmo trutta. Mean $( \pm \mathrm{SE})$ of (A) chloride, (B) glucose, (C) total protein and (D) serum albumen 1 to $5 \mathrm{wk}$ postinfection. $N=15$ for all groups except the Week 5 sample of Week-2-infected fish, $\mathrm{N}=6 . \mathrm{N}=$ total number of fish seawater transfer, but the numbers of lice were extremely low and therefore the significance may not be a true reflection of a faster developmental rate of lice. Overall, the developmental rate of lice on both groups of fish was quicker than previously reported (Johnston \& Albright 1991), but various generation times from 6 to $12 \mathrm{wk}$ have been suggested (Wootten et al. 1982, Tully 1992), dependent on water temperature, water quality and salinity.

Differences in condition factor and feeding between the Week-2- and Week-6-infected fish were observed. In the Week-6-infected fish, suppression of feeding at Weeks 3 and 4 post-infection coincided with preadult lice. The fish infected $2 \mathrm{wk}$ after seawater transfer demonstrated a decrease in condition factor with time and failed to resume feeding by the end of the experiment. Salmon lice cause appetite suppression in artificially infected Atlantic salmon (Anonymous 1997) and seawater transfer has been associated with a suppression of appetite and growth (Jørgensen \& Jobling 1994 , Stead et al. 1996) Therefore, suppression of feeding in the Week-2-infected fish as a consequence of seawater transfer was exacerbated by the appetite suppression induced by lice infection. Fish in the control groups did not resume feeding simultaneously, but as smoltification is a seasonal process and migration is voluntary, smolts in a population will not reach physiological stability and resume feeding at the same time (Usher et al. 1991). Hence, the presence of some non-feeding fish in the control groups was not considered unusual.

No significant differences in dorsal fin erosion were found between the groups, but skin damage was recorded on the head and anal regions and along the dorsal ridge of the infected fish, which was associated with the feeding activities of preadult lice. Head lesions appeared in the Week-6-infected fish before they appeared in the Week-2-infected fish. By the end of the experiment, the Week-2-infected fish had more severe head lesions than in previous weeks, but head damage to the Week- 6 -infected fish was less severe than in the previous week, coinciding with the resumption of feeding and increase in condition of the fish. The pattern of damage observed from the beginning to the end of the experiment in the Week-2infected fish has been attributed to feeding of preadult and adult lice of the parasite (Jónsdóttir et al. 1992, Grimnes \& Jakobsen 1996) and corresponded to the settlement patterns of the different lice stages on the skin of the host (Anonymous 1997). However, the Week-2-infected fish did not display the same pattern of damage and repair as the Week-6-infected fish. Glucose levels, an indicator of stress (Wedemeyer et al. 1980), were elevated, although not significantly, in the fish infected 2 wk after seawater transfer, corresponding with the appearance of head lesions. High levels 
of hydrocortisone retard dermal repair by impairing fibroblast activity (Roubal \& Bullock 1988) and high plasma cortisol levels in lice-infected wild sea trout in Norway have been indicated (Anonymous 1997). Therefore, an increase in stress may explain the delayed repair of the skin damage in the fish infected 2 wk after seawater transfer, indicating that infection with lice during the critical period after seawater transfer hinders the ability of the fish to repair the epidermal layer.

Osmoregulatory failure in Atlantic salmon is associated with an increase in chloride levels and hyperproteinaemia (Grimnes \& Jakobsen 1996). The range of chloride, total protein and serum albumin levels in the control fish were within the range reported for Atlantic salmon (Wedemeyer \& Yasutake 1977, Sandes et al. 1988, Waagbøet al. 1988, Sigholt \& Finstad 1990). No osmoregulatory changes from the control groups were detected in either group of fish in the first 2 wk of infection when the majority of lice were chalimus. The impact of the chalimus on the host is restricted to the size of the radial area around the frontal filament attachment point (Pike 1989) and was insufficient to cause death of the infected host. However, the Week-2infected fish showed an overall increase in chloride levels and a decrease in serum albumen and total protein, associated with the moult to the preadults, appetite suppression and development of skin damage and, hence, osmoregulatory problems. A greater number of fish suffering mortality was recorded in the groups of fish infected 2 wk after seawater transfer at Weeks 4 and 5 post-infection than in the groups of fish infected 6 wk after seawater transfer. In the Week-6infected fish, chloride, total protein and serum albumen levels changed significantly from the control group at 3 wk post-infection but recovered to normal serum levels after the majority of the lice moulted to the adult stages.

In conclusion, sea trout infected during the critical period immediately after seawater transfer had a reduced ability to repair the skin damage caused by preadult lice, leading to osmoregulatory failure and mortality. A period of appetite suppression, induced by the feeding activities of mobile lice, was evident if fish were infected with lice after $2 \mathrm{wk}$ in seawater, resulting in a loss of condition. Severe damage of the dorsal fin by chalimus was insufficient to induce osmoregulatory failure in infected sea trout. Infected trout appeared in the estuaries of rivers for a 3 to $5 \mathrm{wk}$ period after entering seawater, indicating that lice infections occurred within 2 or $3 \mathrm{wk}$ of sea trout migrating to the sea (Tully \& Whelan 1993). Perhaps only those fish with chalimus infections and the lowest numbers of preadults have the ability to return to freshwater and those with greater numbers of preadults suffer mor- tality. This theory is possible as the distribution of Lepeophtheirus salmonis in wild populations is overdispersed (Tully 1992). Therefore, lice infections, as demonstrated by these laboratory experiments, may potentially have a substantial impact on wild fish survival.

Acknowledgements. This work was funded though a CASE award to L. Dawson from the Biotechnology and Biological Sciences Research Council.

\section{LITERATURE CITED}

Anonymous (1991) An investigation into the 1989/90 collapse of sea trout stocks in Galway and South Mayo. Sea Trout News 2:1-23

Anonymous (1997) Report of the interactions between salmon lice and salmonids. ICES CM 1997/M:4 Ref:F: 160

Bolger T, Connolly PL (1989) The selection of suitable indices for the measurement and analysis of fish condition. J Fish Biol 34:171-182

Ellis AE (1981) Stress and modulation of defence mechanisms in fish. In: Pickering AD (ed) Stress and fish. Academic Press, London, p 147-169

Grimnes A, Jakobsen PJ (1996) The physiological effects of lice infection on post-smolt of Atlantic salmon. J Fish Biol 48:1179-1194

Johnston SC, Albright LJ (1991) Development, growth and survival of Lepeophtheirus salmonis (Copepoda: Caligidae) under laboratory conditions. J Mar Biol Assoc UK 71:425-436

Johnson SC, Albright LJ (1992a) Comparative susceptibility and histopathology of the response of naive Atlantic chinook and coho salmon to experimental infection with Lepeophtheirus salmonis (Copepoda: Caligidae). Dis Aquat Org 14:179-193

Johnson SC, Albright LJ (1992b) Effects of cortisol implants on the susceptibility and the histopathology of the responses of the naive coho salmon (Oncorhynchus kisutch) to experimental infection with Lepeophtheirus salmonis (Copepoda: Caligidae). Dis Aquat Org 14:195-205

Jónsdóttir H, Bron JE, Wootten R, Turnbull JF (1992) The histopathology associated with the pre-adult and adult stages of Lepeophtheirus salmonis on the Atlantic salmon, Salmo salar L. J Fish Dis 15:521-527

Jørgensen EH, Jobling M (1994) Feeding and growth of exercised and unexercised juvenile Atlantic salmon in freshwater, and performance after transfer to seawater. Aquacult Int 2:154-164

Le Cren ED (1951) The length and weight relationship and seasonal cycle in gonad weight and condition in the perch (Perca fluviatilis). J Anim Ecol 20:201-219

Maule AG. Schreck CB, Sharpe C (1993) Seasonal changes in cortisol sensitivity and glucocorticoid receptor affinity and number in leukocytes of coho salmon. Fish Physiol Biochem 10:497-506

Pike AW (1989) Lice-major pathogens of farmed and Atlantic salmon. Parasitol Today 5:291-297

Roubal FR, Bullock AM (1988) The mechanism of wound repair in the skin of juvenile Atlantic salmon, Salmo salar L., following hydrocortisone implantation. J Fish Biol 32: 545-555 
Sandes K, Lie $\varnothing$, Waagbo R (1988) Normal ranges of some blood chemistry parameters in adult farmed Atlantic salmon, Salmo salar. J Fish Biol 32:129-136

Sigholt M, Finstad B (1990) Effect of low temperature on seawater tolerance in Atlantic salmon (Salmo salar) smolts. Aquaculture 84:167-172

Stead SM, Houlihan DF, McLay HA, Johnstone R (1996) Effect of ration and seawater transfer on food consumption and growth of Atlantic salmon (Salmo salar) smolts. Can J Fish Aquat Sci 53:685-692

Tully $O$ (1992) Predicting infestation parameters and impacts of caligid copepods in wild and cultured fish populations. Invertebr Reprod Dev 22:91-102

Tully O, Whelan KF (1993) Production of nauplii of Lepeophtheirus salmonis (Krøyer) (Copepoda: Caligidae) from farmed and wild Atlantic salmon (Salmo salar L.) on the west coast of Ireland during 1991 and its relation to infestation levels on wild sea trout (Salmo trutta L.). Fish Res $17: 187-200$

Usher ML, Talbot C, Eddy FB (1991) Effects of transfer to sea-

Editorial responsibility: Wolfgang Körting.

Hannover, Germany water on growth and feeding in Atlantic salmon smolts (Salmo salar L.). Aquaculture 94:309-326

Waagbo R, Sandes K, Espelid S, Lie Ø (1988) Haematological and biochemical analyses of Atlantic salmon, Salmo salar L., suffering from coldwater vibriosis (Hitra disease). J Fish Dis 11:417-423

Wedemeyer GA, Saunders RL, Clarke WC (1980) Environmental factors affecting smoltification and early survival in anadromous salmonids. Mar Fish Rev 42:1-14

Wedemeyer GA, Yasutake WT (1977) Clinical methods for the assessment of the effects of environmental stress on fish health. US Fish Wildl Serv Tech Pap 89:1-14

Woo PTK, Shariff M (1990) Lernaea cyprinacea L. (Copepoda: Caligidae in Helostoma temmicki Cuvier and Valanciennes: the dynamics of resistance in recovered and naive fish. J Fish Dis 13:485-493

Wootten R, Smith JW, Needham EA (1982) Aspects of the biology of parasitic copepods, Lepeophtheirus salmonis and Caligus elongatus on farmed salmonids and their treatment. Proc R Soc Edin Sect B (Biol) 81:185-197

Submitted: March 23, 1998; Accepted: April 14, 1998

Proofs received from author(s): July 9, 1998 